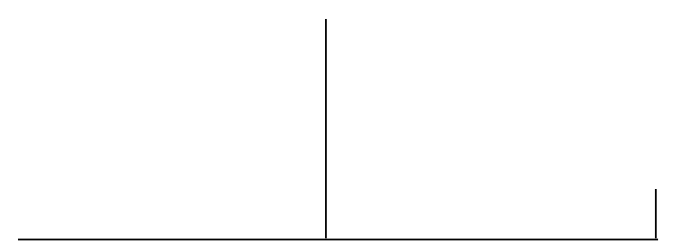

Rev. Latinoam. Psicopat. Fund., São Paulo, v. 13, n. 1, p. 87-101, março 2010

\title{
Do amor à amizade na psicose: contribuições da psicanálise ao campo da saúde mental*
}

Nuria Malajovich Muñoz

\begin{abstract}
O trabalho tem como fundamento as elaborações de Lacan para examinar o lugar do amor na relação que o psicótico estabelece com o mundo. As dificuldades relativas ao amor na psicose exigem uma abordagem particular da transferência visando à invenção de novas formas de enlace do sujeito com o mundo. A retomada das origens gregas da amizade, através da philia, nos ajudará a compreender como pode se dar a criação e a sustentação de uma amizade de transferência. A procura e a construção de uma solução possível para a transferência será evidenciada discutindo o seu manejo no coletivo.
\end{abstract}

Palavras-chave: Psicose, amor, psicanálise, saúde mental

* Este artigo deriva-se da Tese de Doutorado em Teoria Psicanalítica: N. M. Muñoz, Inventar o amor: um desafio para a clínica das psicoses, 2005. Universidade Federal do Rio de Janeiro. 
A prática de cuidado com a psicose no campo da saúde mental requer o desafio cotidiano de construir estratégias e intervenções que auxiliem os sujeitos a encontrar um enlace particular com o social. Trata-se, a cada caso, de inventar uma modalidade única de resposta a ser oferecida como produto de um encontro. Para que se possa realizar um manejo individualizado das soluções sintomáticas é necessário extrair a lógica que rege o seu funcionamento. Por mais disruptivos ou originais que sejam, os sintomas devem ser considerados como respostas que visam lidar com o mal estar. Uma prática normativa ou universal é assim descartada, exigindo disposição para inventar cotidianamente estratégias de cuidado individualizadas.

Diante da multiplicidade de soluções da psicose, e do fato de que a norma e o senso comum não atuam como elementos ordenadores desta modalidade clínica, cabe a tarefa de encontrar instrumentos que façam uma mediação eficaz na relação do sujeito com o mundo. A modalidade de resposta oferecida pode tomar apoio em um estilo de presença (Zenoni, 1993) a ser adotado pela equipe técnica, de modo a minimizar os efeitos dispersivos ou totalizadores da convivência cotidiana. Advertidos acerca dos riscos e fragilidades do laço social na psicose, devemos incentivar formas de estar no mundo que não forcem o sujeito a uma ruptura ou a uma exclusão. Visa-se, assim, oferecer um lugar ao sujeito que acolha as suas manifestações e lhes proporcione um endereço. A presença ativa de alguém que aceite se colocar no lugar de destinatário e dê testemunho de 
recebimento daquilo que lhe foi endereçado localiza a produção psicótica, podendo deixar o sujeito mais livre para encontrar novas formas de enlace com o social.

No plano da transferência, o amor é a condição de produção de um tratamento, seja ele de neurose ou de psicose (Brousse, 1999). Mas, no que concerne à psicose, essa constatação não torna a tarefa menos complexa, já que o amor também costuma ser mortificante. Na falta de uma regulação prévia, a relação com um parceiro pode estar na base de um desencadeamento ou de uma desestabilização. A dualidade que costuma se estabelecer entre o sujeito e o outro na psicose deixa pouca margem à entrada de terceiros ou de qualquer elemento que se coloque em seu lugar. Na impossibilidade de encontrar algo que venha fazer função de mediação, pode-se viver o amor não enquanto agente, mas enquanto vítima dele. O excesso do Outro faz com que o sujeito não encontre outro lugar que não seja o de se fazer de seu objeto.

Se há dificuldades do psicótico do lado do amor, o que dirá em relação à sustentação do laço transferencial? Como pode se dar então o tratamento do sujeito psicótico? Essas perguntas são pertinentes à medida que - pela estrutura de inversão própria à lógica da psicose e que se dá principalmente em suas vertentes paranoica e paranoide (Zenoni, 2006) - a transferência se localiza primordialmente do lado do Outro e não do lado do sujeito. A erotomania e a perseguição são, por isso, riscos concretos no horizonte desse tipo de tratamento. O sujeito não vive a paixão enquanto agente e pode ser, portanto, amado, traído ou odiado por aquele que aceitar se colocar no lugar do Outro. As virtualidades mortíferas do amor se concretizam, então, em três riscos: a destruição da paixão, do sujeito ou de seu objeto.

A manobra clínica visa efetuar um deslocamento dessa posição primeira na qual se é instado pela transferência a ocupar. Como indica Leguil (2007), é necessário que se tome a transferência em consideração para que não se prejudique o sintoma, embora essa constatação não seja suficiente para solucionar as dificuldades oriundas de seu manejo. Se o método clínico da neurose fracassa quando aplicado à psicose, a transferência pode tomar a forma de erotomania mortificante (Lacan, 1966). É preciso esquivar-se da posição do Outro todo, sem furo, mantendo-se, ao mesmo tempo, à distância do lugar do igual, dado o risco de um resvalamento inadvertido para o lugar indesejado do rival.

Fica evidente o quão delicada pode se tornar uma sustentação da rotina diária de um serviço, e o quanto dificuldades advindas do convívio podem concretizar um risco persecutório. Investir para que o psicótico adquira um lugar de 
protagonismo em seu tratamento e se aproprie acerca de sua história e de seu adoecimento pode funcionar como um bom antídoto contra o excesso transferencial. É necessário, para este fim, que se consinta em dar voz ao sujeito em relação àquilo a que se refere o seu projeto terapêutico, acompanhando seus movimentos no seu encontro com a equipe, evitando recorrer ou moldar as intervenções em um saber prévio que o situaria como um simples objeto de cuidados. É preciso também estar atento para que o exercício de fala não se torne excessivo ou desestabilizador, pois falar não necessariamente apazigua, podendo, pelo contrário, deixar o sujeito à mercê de sua indeterminação.

A distribuição em rede proposta pelo campo da saúde mental visa a participação de várias instâncias comunitárias, ampliando os recursos com os quais o sujeito pode contar para a sua estabilização. Além disso, mostra o papel fundamental que pode adquirir o furo na sustentação desse tipo de laço: a partir dos pontos que tecem a rede constroem-se buracos, ou seja, a ligação dos elementos constitui um vazio, formando assim pequenas distâncias, intervalos, espaços que permitem ao psicótico manter-se ao abrigo do lugar penoso de objeto.

Esse tipo particular de enlace promove a construção de um saber fazer do lado do psicótico que implica no estabelecimento de uma prudência estratégica em relação aos pontos que geram conflito e desorganização (Miller, 2003). A relação transferencial pode auxiliar a desenvolver truques, formas de lidar com os sintomas e seus aspectos invalidantes, encontrando um modo próprio de estar no mundo. Como assinala Corin (2003), uma posição de retraimento pode estar ligada à manutenção no meio de vida, ou seja, por meio da criação de uma relação de distância com o mundo social pode-se encontrar uma forma eficiente de se manter afastado, mas com os outros.

O laço transferencial deve preservar na psicose a manutenção de uma certa distância em sua estruturação de modo a não invadir o sujeito e minimizar uma possível mortificação. Esvaziar o Outro é uma tarefa que pode ser sustentada pela construção - apesar do fracasso do amor - de uma amizade de transferência. A retomada das origens aristotélicas da amizade, através da philia, ${ }^{1}$ nos ajuda a

1. Segundo Benveniste (1976), a palavra philos, que designava primeiramente tudo aquilo que é "caro", foi assimilada ao possessivo "meu", tendo seu sentido reunido na expressão "meu caro". A posse é assim expressa a partir de duas formas imediatas: o pertencimento e a proximidade. Philos tem um caráter jurídico - um objeto é qualificado de philos pelo seu proprie- 
compreender como pode se dar a sua manutenção. É importante assinalar que a filosofia clássica utilizou-se de duas palavras distintas para o amor: philia e Eros. Sabemos que Lacan (1960-1961) propôs pensar o Sujeito Suposto Saber na neurose a partir das ideias contidas no Banquete de Platão. Nossa hipótese é de que a philia aristotélica nos permitirá deduzir algumas direções relativas ao modo de transferência na psicose.

O termo philia caracterizava-se em Aristóteles (2005) por um determinado conjunto de comportamentos que tinham por objetivo o estabelecimento de um pacto de hospitalidade entre membros de uma comunidade. Originalmente, em Homero, esse termo remetia à possibilidade de acolher o estrangeiro (Ortega, 2004), passando posteriormente a estar, por esse motivo, na base das relações de toda comunidade. Inaugura-se assim um tipo de laço definido por uma ética que determina o estabelecimento de vínculos e compromissos recíprocos.

Para Aristóteles (2005), ao contrário de Platão, a philia se refere à ordem estritamente humana. As dificuldades ligadas à sua consecução são colocadas e resolvidas nos limites da ética. Sua condição de determinação se liga ao bem, entendido aqui não como algo transcendente, mas como um valor concreto. A amizade é um conceito ético que implica um pacto que supõe um conjunto de ações que visam o bem do outro enquanto outro. A philia ganha assim o sentido de amizade cívica, sentimento de pertencimento que liga entre si os membros de uma mesma comunidade. A amizade é definida sobre um fundo de presença e de comunidade partilhada, baseada na experiência concreta de uma comunidade.

Encontramos interessantes indicações sobre a philia na obra de Lacan que a considera, seguindo Aristóteles, como um amor privado do sexual. É assim que intitula o laço que uniu Schreber a sua esposa (Lacan, 1957-1958), indicando o lugar estratégico por ela ocupado para a viabilização da confecção das memórias e sua publicação em livro. A philia matrimonial constitui-se para Schreber como um dos pontos fortes de sua estabilização. Apesar da relação fora do eixo com o Outro, a manutenção de seu relacionamento marital se fez possível ao preço de uma renúncia ao sexual. A segunda indicação lacaniana (1970) mostra que

tário. Tratar bem a alguém é philein, ou seja, não significa necessariamente que seja tido em grande afeição, mas que os cuidados necessários lhe são prestados, cumprindo as ações positivas que o pacto de hospitalidade implica. Nessa mesma linha, Milner (1999) mostra que philos remete originalmente a uma relação institucional não afetiva. 
o exercício e a coragem de suportar a relação intolerável ao Outro, enquanto ser supremo, sustenta a amizade como philia e assinala o caráter fora do sexo da ética que deriva dessa orientação.

Descreveremos, a partir de duas situações extraídas da prática de cuidado no campo da saúde mental, o percurso clínico que possibilitou o estabelecimento da transferência enquanto philia, enfatizando como, a partir de uma manobra específica facilitada pela distribuição em rede, cada um dos sujeitos pôde encontrar uma distância necessária que lhes permitiu a efetivação de um enlace particular com o mundo.

\section{A amizade e a prática da boa distância ${ }^{2}$}

\section{"Você atua em prol da pessoa, não fica me sofismando"}

Um paciente do CAPS, de aproximadamente trinta anos, situa o início de seus problemas aos 14 anos, quando se apaixonou por uma menina de sua turma. Passa a sentir que exala um cheiro ruim que o leva a se afastar das meninas e da escola, e a tentar repetidamente o suicídio. Inúmeras automutilações, enorme dificuldade em vincular-se a atividades terapêuticas, laborativas ou até mesmo em frequentar o cotidiano do CAPS. São constantes queixas de que o mundo, mas principalmente seus vizinhos, técnicos e usuários o humilham por causa de seu cheiro. Sente não ser benquisto no seu bairro e no CAPS, crê que tudo de ruim que acontece lhe é atribuído.

À menor ação ou interferência da equipe foge, para retornar, em um segundo tempo, todo cortado e ensanguentado: "As pessoas querem que eu frequente o CAPS, mas não entendem que o meu caso é muito grave. Eu já tentei várias vezes o suicídio". O entendimento de que no seu caso o coletivo podia ter um efeito muito dispersivo e mesmo devastador fez com que a equipe tentasse se manter cada vez mais isenta frente aos seus projetos, dizendo-lhe apenas que era "bemvindo" e que o CAPS se mantinha disponível para ajudá-lo. Além disso, a equipe

2. As situações clínicas descritas referem-se ao acompanhamento de dois casos atendidos, respectivamente, em um CAPS e em um ambulatório da Rede Pública de Saúde do Município do Rio de Janeiro. 
se empenhou em reforçar o endereçamento transferencial que o usuário havia me dirigido, remetendo-o ao seu atendimento individual, de forma acolhedora e cuidadosa, a cada vez que procurava alguém para falar de seus problemas.

A oferta de um espaço individual onde pudesse compartilhar os efeitos e os destinos que o amor causou em sua vida ocasiona uma invenção. Exerce, suportado pelo dispositivo transferencial, o "amor aos livros", ocasião na qual consegue doar um pouco de seu saber por meio da função de ler. A leitura de uma história na qual um amigo salva o outro da morte, apesar de todos os percalços pelos quais precisa passar para isso, localiza o lugar na transferência. Diz: "Eu não tenho amigos". Acrescenta, após um breve silêncio: "Você é minha amiga. Só venho ao CAPS em consideração a você".

A amizade de transferência promove assim uma sustentação mínima que torna possível o lugar "de poder ler um pouco para alguém". Restringir os espaços de fala aos atendimentos individuais foi uma importante estratégia coletiva para tentar dar à sua fala um suporte, um continente. Por outro lado, dirigir a fala a alguém específico possibilitou a retomada, mesmo que pontual, da convivência no CAPS.

\section{Das testemunhas à confiança}

Homem de quarenta anos é recebido para atendimento individual em ambulatório a pedido da coordenação da unidade. Situa o desencadeamento durante a faculdade, a partir do namoro com uma colega. Começa a sofrer perseguições, vodu, magia negra. Abandona qualquer atividade, mas sonha em ser cozinheiro. Demonstra-se indisposto a se submeter a uma psicoterapia, afirmando que não há sigilo possível para ele.

Falar é, para ele, trazer a público. Sua vida é devassada, invadida e comentada, sente que seus pensamentos são roubados e difundidos na rádio, no jornal e na televisão. Uma enxurrada de solicitações gira em torno da ideia de que eu, enquanto psicóloga, devo fazer alguma coisa para ajudá-lo, para defendê-lo publicamente das acusações das quais se sente alvo. Um período difícil se anuncia: ataques de fúria, pedidos incessantes e uma indisponibilidade de permanecer no tempo do atendimento. A ausência de uma resposta da minha parte é tomada por ele como descaso ou como incompetência. Ameaça constantemente deixar o atendimento, pede com frequência para ser encaminhado a outro profissional. 
Após o retorno de minhas férias, apresenta-se ainda mais contrariado, recusando-se a me dirigir a palavra. Sem aprofundar a razão de seu descontentamento, deixa entrever, contudo, que a transferência estava tomando um colorido persecutório: "A partir de agora só quero conversar com você se houver testemunhas presentes". Acato a sua solução e proponho que participe de um grupo terapêutico no qual atuava e que era composto por uma equipe multiprofissional. A reconfiguração da modalidade de cuidado ofertado institui uma manobra que apazigua a relação, redirecionando a transferência para um dispositivo mais coletivo.

Paralelamente, inicia um trabalho intenso de escrita, não sem se queixar de que as pessoas fazem apropriações e licenças sobre os seus escritos. Teme que estes sejam roubados como material para elaboração de roteiros de uma importante rede de televisão. Decide então confiar-me a guarda desse material, afirmando que sou a sua única amiga. São pedaços de papel com fragmentos de falas escutadas, pensamentos, ou ainda breves acontecimentos meticulosamente numerados. Compra uma pasta e pede que eu organize seus escritos respeitando a numeração que havia estabelecido.

Os atendimentos individuais são então retomados mantendo o grupo terapêutico como mediador e, ao mesmo tempo, como uma proteção contra a possível reintensificação da transferência. Passa a poder recorrer a consultas extras quando se sente muito invadido ou difamado, ou quando deseja solicitar o meu aval sobre determinada solução. Engaja-se (pela primeira vez em dez anos) em uma atividade: confecciona utensílios domésticos. Apesar das dificuldades, das cismas e das desconfianças, consegue vender algumas peças. Após um tempo, conclui um curso de pastelaria. Em agradecimento, presenteia a equipe com sonhos por ele confeccionados.

\section{O amor mortificante}

Em uma de suas lições concernentes ao estudo da psicose, Lacan (19551956) situa que a diferença entre um neurótico e um psicótico coloca-se no fato de que, para este último, o amor é morto. O amor promove uma abolição do sujeito na psicose ao admitir uma "heterogeneidade radical do Outro" (p. 287). Para explicar a relação amorosa do sujeito com esse Outro absoluto, sem furo, Lacan 
recorre à teoria medieval do amor, em particular àquela que fala da relação extática com a alteridade. Indica com isso o quanto o amor na psicose pode ser mortificante, exigindo que o sujeito se ofereça como objeto, sacrificando-se em nome do Outro absoluto.

Para circular pelo sentido do senso comum, é necessária a integração em um certo jogo significante. É também por meio do significante que se tem acesso à vertente feminina e masculina da sexualidade. Na psicose, as desventuras do amor vão se ligar à fragilidade de sua estruturação significante e à escassez de recursos para lidar com a diferença sexual: “A psicose é uma espécie de fracasso no que concerne ao cumprimento daquilo que é chamado 'amor"” (Lacan, 1975, p. 35).

Com as últimas teorizações lacanianas, podemos inferir que o psicótico fracassa em adotar a solução típica, a norma padrão que viabilizaria o encontro entre os sexos. O sujeito fica vulnerável à linguagem, podendo, durante o surto, ser habitado por ela. A desestabilização na psicose acarretará toda uma série de fenômenos imaginários concernentes ao ser sexual do sujeito e à representação do que é para ele, dependendo do sexo ao qual pertença, ser homem ou ser mulher.

A renúncia ao sexual pode ser uma solução na psicose, o platonismo se coloca algumas vezes como um anteparo eficiente contra o excesso de gozo. De fato, muitos psicóticos estabilizados dizem ter claramente renunciado ao sexual, assim como outros não chegam nem a considerá-lo como uma possibilidade concreta em suas vidas. Devemos, contudo, frisar que essa não é uma regra geral, e que há depoimentos clínicos que mostram sujeitos que conseguiram inventar soluções para construir um limite ou uma borda para lidar com o a mais que acompanha o sexual na psicose. Vieira (2002) relata como a falta de um atributo específico no corpo da amante localiza um furo que permite ao paciente acessar o seu corpo. Borie (2002) descreve como uma montagem, feita de restos, pedaços e dejetos, serve de enquadre e pacifica a relação sexual.

$\mathrm{O}$ amor morto é aquele que pode exibir a morte do sujeito em seu horizonte. Leguil (1987) aponta que devemos utilizar as teorizações lacanianas a respeito da alucinação como um contraponto para a clínica psicótica do amor. Pelo fato de o amor poder ser vivido em sua exterioridade mais radical, assim como na alucinação, ele interroga a posição do sujeito e deve ser tomado em termos daquilo que lhe é relativo: como certeza de que, daquilo de que se trata, lhe concerne. A palavra de amor, a injúria e a alucinação veiculam uma certeza que concerne ao sujeito em seu ser, mas, por uma inversão, esta certeza vem do Outro e não do sujeito. 
A alucinação e o amor podem situar o sujeito em uma posição subjetiva, apesar deste lugar muitas vezes o desmerecer ou o denegrir. $O$ amor na psicose não está, assim, disjunto do gozo excessivo e mortificante do Outro, mas, ao contrário, pode convocá-lo. Esse aspecto do amor na psicose pode ser considerado como um dos nomes do efeito, no sujeito, do gozo do Outro. Em oposição ao sujeito da neurose, cuja aparição entre os significantes é pontual e evanescente, Lacan (1966) proporá pensar o sujeito na psicose como sendo um sujeito de gozo.

A partir da constatação de que não é incomum que um vizinho ocupe, para um sujeito psicótico, o personagem central de seu delírio persecutório, Laurent (1989) propõe pensar que o problema da transferência na psicose pode se exemplificar como estando do lado do vizinho malvado: "A erotomania de transferência é a articulação entre o amor e o gozo malvado que pode ser localizado (...) do lado do vizinho" (p. 15). Esse comentário remete aos problemas relativos à organização diária de um serviço. Como lidar com a intrusão que pode advir da proximidade da convivência cotidiana em um dispositivo do tipo CAPS? Não é incomum que usuários se afastem do dia-a-dia do serviço em momentos nos quais a transferência, por determinado técnico ou estagiário, se torna muito intensa.

O coletivo institucional pode ter um peso excessivo para o sujeito psicótico que, por vezes, pode não suportar o convívio e a proximidade com aquele que se oferece para ser o destinatário de suas produções. Mas a recíproca também é verdadeira. Como mostramos, o atendimento individual em ambulatório pode ser dificultado pelos riscos transferenciais próprios à psicose, sendo por isso interessante que se possa contar com uma equipe multiprofissional de modo a, eventualmente, redirecionar a transferência para um dispositivo mais coletivo.

\section{Da amizade ao saber}

A descoberta do papel que a transferência pode ocupar em um tratamento desvelou a relação entre amor e saber. Lacan (1972-1973) explicitou que na neurose ama-se àquele a quem se supõe deter o saber que viria a nos completar. Todo o problema da transferência na psicose gira em torno dessa questão já que, à medida que o amor e o gozo encontram-se aí intrincados, ocupar o lugar de saber na transferência pode equivaler a firmar-se na posição de Outro gozador. O saber na psicose está e deve permanecer, portanto, do lado do sujeito. É ele quem 
sabe sobre as investidas do Outro, que podem se apresentar, por exemplo, sob a forma de amor, de gozo desmedido ou de alucinação.

Estar advertido sobre o caráter passional que o laço com o outro pode tomar na psicose pode ser útil no trabalho com a transferência. Essa constatação é fundamental, pois não é incomum que se assumam, na prática em instituição, condutas disciplinares a partir da pressuposição errônea de que temáticas passionais sejam exclusivas ou até mesmo determinantes de um funcionamento neurótico. Chama-se, assim, o sujeito a subordinar-se à lei, muitas vezes encarnando-a e exigindo do sujeito que deixe de encenar o seu sofrimento. A psicanálise mostra que chamar um sujeito psicótico à razão pode, paradoxalmente, forçar uma desconexão e propiciar um desenlace do sujeito com o mundo.

Se o amor na psicose visa o sujeito e o constrange, a amizade de transferência pode impulsioná-lo em uma via de construção de uma invenção de saber que dê conta das investidas sem sentido do Outro, ou na criação de um artefato que faça barreira aos seus abusos. É possível que o psicótico se ponha a construir uma teoria sobre o amor, mas se o amor do qual se trata aqui não é marcado pela armadura fálica, o laço inusitado com o saber poderá situá-lo do lado da criação, como uma invenção de saber particular e original.

No livro La pareja y el amor, autores do Campo Freudiano discutem a respeito das possibilidades do amor na psicose. Mostram que, se por um lado, a vivência do amor muitas vezes fracassa, isso pode liberar o sujeito na direção do saber e viabilizar o estabelecimento de um laço de transferência. Miller (2003) propõe a esse respeito a seguinte fórmula: "Fracasso do amor, êxito do saber" (p. 274). Esclarece ainda que esse saber tem o estatuto de um saber fazer, cabendo-nos auxiliar o sujeito a decidir quais caminhos deve trilhar, e com quais pensamentos e problemas não deve se ocupar, ou seja, em como fazer para se manter a uma certa distância do Outro e de seus entraves.

Essa perspectiva traz uma nova luz ao lugar de secretário do alienado apontado por Lacan (1955-1956), e mostra que se fazer de destinatário do testemunho do psicótico é mais do que exercer a função de um simples "tomador de notas". Ao se acolher e privilegiar determinadas coisas em detrimento de outras, toma-se uma certa posição clínica (Laurent, 1997). É necessário, portanto, que por meio de uma aposta se receba e se reconheça determinado signo como produto de um endereçamento. Uma orientação coletiva acerca da prática serve então para, no mínimo, não atrapalhar o trabalho individual e espontâneo da psicose, pois as soluções estarão sempre do seu lado. 
A philia pode auxiliar o psicótico a encontrar uma regulação que contribua para a criação de uma defesa contra o desejo do Outro, sem precisar para isso fazer recurso ao pai ou à norma fálica. Como mostra Hanna (2000) ao nos fazermos de destinatários das produções psicóticas, assumimos a dimensão de semelhante, o que "introduz uma diferença: isto é, não se trata do mesmo" (p. 132). A philia, enquanto solução transferencial na psicose, coloca os responsáveis pelo seu cuidado do lado do sujeito frente ao Outro, o que, por sua vez, contribui para a regulação deste último. Além disso, esvazia o colorido sexual da transferência permitindo a instauração de um laço apaziguador para aquele sujeito que já sofreu, em sua subjetividade, as consequências do desencadeamento psicótico. A invenção de uma distância permite a apropriação daquilo que aparece como inicialmente vindo do Outro, limitando e mantendo afastado o perigoso lugar de absoluto. No que se refere ao dispositivo da clínica ampliada, sua organização potencializa a circulação dos saberes inéditos dos sujeitos, ponto no qual a philia encontra a sua função: ao promover uma distância entre os sujeitos, instaura a possibilidade de um mundo passível de ser compartilhado.

\section{Referências}

Aristóteles. Ética a Nicômaco. São Paulo: Martin Claret, 2005.

Benveniste, E. Problèmes de linguistique générale. Paris: Gallimard, 1976.

Borie, J. Une version de la vie sexuelle sans le phallus. In: Miller, J-A. (Org.). L'amour dans les psychoses. Paris: Seuil, 2004.

Brousse, M-H. L'incidence du transfert dans la clinique des psychoses. In: $L a$ stylistique des psychoses. Paris: Documents préparatoires de l'ICF, 1999. p. 81-88.

Corin, E. À l'ombre de la psychose. Des tracés en creux aux marges de la culture. Cahiers de Psychologie Clinique, n. 21, p. 197-218, 2003.

Hanna, M. S. A transferência na psicose: uma questão. 2000. 174 p. Tese (Doutorado em Teoria Psicanalítica). Universidade Federal do Rio de Janeiro.

LaCAN, J. (1955-1956). O seminário. Livro 3. As psicoses. Rio de Janeiro: Jorge Zahar, 1985. . (1957-1958). De uma questão preliminar a todo tratamento possível das psicoses. In: Escritos. Rio de Janeiro: Jorge Zahar, 1998. 


\section{SAÚDE MENTAL}

. (1960-1961). O seminário. Livro 8. A transferência. Rio de Janeiro: Jorge Zahar, 1992.

. (1964). Le séminaire. Livre 11. Les quatre concepts fondamentaux de la psychanalyse. Paris: Seuil, 1973.

. (1966). Apresentação das Memórias de um doente dos nervos. In: Outros escritos. Rio de Janeiro: Jorge Zahar, 2003.

. (1967). Petit discours aux psychiatres. Bibliothèque Pas-tout Lacan. Disponível em: <http://www.ecole-lacanienne.net/pastoutlacan60.php>. Acesso em: 11/8/2009. . (1972-1973). O seminário. Livro 20. Mais, ainda. Rio de Janeiro: Jorge Zahar, 1985.

. Conférences et entretiens dans des universités nord-américaines. Scilicet, Paris, n. 6/7, p. 32-37, 1975.

Leguil, F. A propos d'um cas d'anti-érotomanie. In: L'expérience psychanalytique des psychoses. Actes de l'ECF, Paris, p. 52-54, 1987.

. Não há clínica da fumaça sem fumante. In: Pertinências da psicanálise aplicada. Rio de Janeiro: Forense Universitária, 2007.

LaURent, E. Estabilizaciones en las psicosis. Buenos Aires: Manantial, 1989. . L'appareil du symtôme e Dernier tout de parole. La Conversation d'Arcachon. Cas rares: les inclassables de la clinique. Paris: Seuil, 1997.

Miller, J-A. La conversation d'Arcachon. Cas rares: les inclassables de la clinique. Paris: Seuil, 1997.

Miller, J-A. (Org.). La pareja y el amor. Buenos Aires: Paidós, 2003.

MiLner, J-C. Lo triple del placer. Buenos Aires: Ediciones del Cifrado, 1999.

Ortega, F. Genealogias da amizade. São Paulo: Iluminuras, 2002.

Zenoni, A. Clinique psychanalytique en institution: la psychose. Les Feuillets psychanalytiques du Courtil, n. 7, p. 77-92, 1993.

. Comment s'orienter dans le transfert. Revista Clínicas: Impasses da Clínica, n. 1, 2006. Disponível em: <http://www.clinicaps.com.br clinicaps_revista_0101_ sum.html $>$. Acesso em: 11/8/2009.

Vieira, M.A. Dans le trou du désert. In: Miller, J-A (Org.). L'amour dans les psychoses. Paris: Seuil, 2004. 


\section{Resumos}

(Del amor a la amistad en la psicosis: contribuciones del psicoanálisis en el campo de la salud mental)

El trabajo tiene como eje las elaboraciones de Lacan y examina el lugar del amor en la relación que el psicótico establece con el mundo. Las dificultades relativas al amor en la psicosis requieren un enfoque particular de la transferencia, de manera a inventar nuevas formas de lazo entre el sujeto y el mundo. La retomada del origen griego de la amistad, a partir de la philia, nos ayudará a entender cómo se puede crear y sostener una amistad de transferencia. La busca y la construcción de una posible solución para la transferencia sera demostrada, discutiendo su manejo en el colectivo.

Palabras claves: Psicosis, amor, psicoanálisis, salud mental

(De l'amour à l'amitié dans la psychose: contributions de la psychanalyse au domaine de la santé mental)

A partir des élaborations de Lacan, nous examinerons le rôle de l'amour dans la relation du psychotique avec le monde. Les difficultés de l'amour liées à la psychose exigent une approche particulière du transfert, de façon à produire de nouvelles formes de liaison du sujet avec le monde. La reprise de l'origine grecque de l'amitié, a partir de la philia, nous aidera à comprendre de quelle façon se crée et se soutient une amitié de transfert. La recherche et la construction d'une solution possible pour le transfert seront attestées, tout en discutant son maniement dans le collectif.

Mots clés: Psychose, amour, psychanalyse, santé mentale

(From love to friendship in psychosis: contributions of psychoanalysis to the field of mental health)

The basis for this article lies in Lacan's developments for examining the role of love in the relationship psychotic patients establish with the world. The difficulties concerning love in psychosis demand a specific approach to transference in order to create new ways for the subject to bond with the world. Tracing back to the Greek origins of friendship, denoted by the term philia, will help us understand how one can develop and maintain a transference friendship. The search for and construction of a possible solution for transference is presented and its management in the collective experience is discussed.

Key words: Psychosis, love, psychoanalysis, mental health 
Citação/Citation: MuÑoz, N.M. Do amor à amizade na psicose: contribuições da psicanálise ao campo da saúde mental. Revista Latinoamericana de Psicopatologia Fundamental, São Paulo, v. 13, n.1, p. 87-101, mar. 2010.

Editor do artigo/Editor: Prof. Dr. Ana Cristina Costa de Figueiredo

Recebido/Received: 6.4.2009/4.6.2009 Aceito/Accepted: 19.12.2009/12.19.2009

Copyright: () 2010 Associação Universitária de Pesquisa em Psicopatologia Fundamental/University Association for Research in Fundamental Psychopathology. Este é um artigo de livre acesso, que permite uso irrestrito, distribuição re reprodução em qualquer meio, desde que o autor e a fonte sejam citados/ This is an open-acess article, which permits unrestricted use, distribution, and reproduction in any madium, provided the original author and source are credited

Financiamento: O autor declara não ter sido financiado ou apoiado/ The author has no support of funding to report.

Conflito de interesses: $O$ autor declara que não há conflito de interesse/ The author declares that has no conflict of interest

\section{Nuria Malajovich Muñoz}

Doutora em Teoria Psicanalítica pelo Instituto de Psicologia da Universidade Federal do Rio de Janeiro - UFRJ (Rio de Janeiro, RJ, Brasil); professora adjunta do Departamento Interdisciplinar de Rio das Ostras da Universidade Federal Fluminense - UFF (Rio das Ostras, RJ, Brasil).

Rua General Glicério 326/603

22245-120 Rio de Janeiro, RJ, Brasil

e-mail: nuria@rio.com.br 